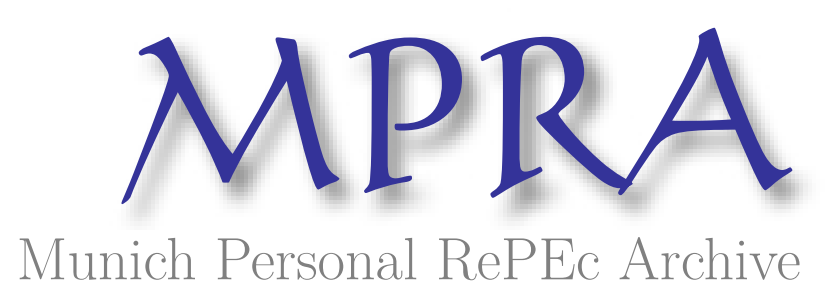

\title{
Environmental management in Bulgarian agriculture
}

Bachev, Hrabrin

Institute of Agricultural Economics

March 2008

Online at https://mpra.ub.uni-muenchen.de/7769/

MPRA Paper No. 7769, posted 15 Mar 2008 17:03 UTC 


\title{
Environmental Management in Bulgarian Agriculture
}

\author{
Hrabrin Bachev ${ }^{1}$ \\ Institute of Agricultural Economics, Sofia, Bulgaria
}

\begin{abstract}
This paper presents a new framework for analysis and improvement of environmental management based on the achievements of the New Institutional and Transaction Costs Economics. Following that new framework we first, identify the major environmental problems and risks in Bulgarian agriculture. Next, we access efficiency of market, private and public modes of environmental management employed in the sector. And finally, we give prospects and major challenges of environmental management in conditions of EU Common Agricultural Policy implementation.

Our analysis shows that post-communist transition of Bulgarian agriculture has changed the state of the environment and brought some new challenges such as: degradation and contamination of farmland, pollution of surface and ground waters, loss of biodiversity, significant greenhouse gas emissions etc. Badly defined and enforced environmental rights, prolonged process of privatization of agrarian resources, carrying out farming in structures not motivating in long-term investment, low appropriability of certain environmental rights and high uncertainty and assets specificity of environment related transactions, all these factors have been responsible for failure of market and private modes of environmental management. The strong needs for a public intervention have not been met by an effective government, community, international assistance etc. intervention. Consequently agrarian sustainability has been severely compromised.

The assessment of likely impact of EU CAP implementation under "Bulgarian" conditions indicates that the main beneficiary of various new support measures will be the biggest operators. Income, technological and environmental discrepancy between different farms, sub-sectors and regions will be further enhanced. Our analysis has been also supported by field survey data from different type dairy farms from two major milk producing regions of the country. We have found out that a great number of farms have no sufficient capacity for adaptation to new EU requirements for the dairy sector. The bulk of milk producers expect no positive impact of CAP measures on their income, volume and technology of production, investment level, product quality, access to public programs, improvement of environmental care, improvement of animal welfare, development of infrastructure, possibilities for new income generation, and social status of farm households.
\end{abstract}

Key words: environmental management; market, private and public governance; agrarian transition; CAP implementation; governing agrarian sustainability; comparative institutional analysis; transaction costs; Bulgaria

\footnotetext{
${ }^{1}$ Correspondence should be addressed to Hrabrin Bachev, Institute of Agricultural Economics, 125 Tzarigradso Shosse Blvd. Block 1, 1113 Sofia, Bulgaria; e-mail: hbachev@yahoo.com
} 


\section{Introduction}

Environmental management is one of the important aspects of sustainable agrarian development. It is increasingly a hot topic of interest of policy makers, academicians, agrarian and rural agents, business community, interests groups, and final consumers. There have been a number of studies on specific environmental problems in transitional countries from Central and East Europe (Gatzweiler and Hagedorn, 2003; Sumelius, 2000) including Bulgaria (Bentcheva and Georgiev, 1999). With few exceptions (Bachev 2008) there are no comprehensive studies on up to date environmental problems and risks in Bulgarian agriculture, and specific modes of environmental governance applied during transition and EU integration, and likely prospects of modernization of environmental management in conditions of EU membership.

In this paper we incorporate a new developing interdisciplinary methodology of the New Institutional and Transaction Costs Economics based on the contributions of Coase (1960), Furuboth and Richter (1998), North (1990), and Williamson (1996). Comparative institutional analysis is employed to evaluate potential of diverse governing modes to deal with environmental problems and risks, protect absolute and contracted eco-rights, stimulate eco-investment, intensify and coordinate eco-activities etc. Firstly, we present a new framework for analysis and improvement of environmental management; next, we identify the major environmental problems and risks in Bulgarian agriculture; third, we access efficiency of market, private and public modes of environmental management employed in the sector; and finally, we give prospects and major challenges of environmental management in conditions of EU CAP implementation.

\section{Framework of analysis}

Environmental management means governance of environment preservation and environment improvement activities of various agents. It requires a system of coordination and stimulation of eco-actions at different levels - individual, group, community, regional, national, and more often transnational and global. The environmental preservation and improvement could be achieved through a range of market, private, collective, public and hybrid modes of governance. Efficiency of individual modes of management is quite different in the specific institutional and natural environment of each community, industry, region, and country. On the other hand, depending on the particular form(s) of governance individual societies achieve quite unlike results in environmental conservation and enhancement ("governance matters").

The New Institutional and Transaction Costs Economics gives a new insight on the comparative efficiency of divers market, private, public and mix modes of governance, and their potential to deal with various environmental problems and risks (Bachev, 2004; Bachev, 2007a). It requires embracing all modes of governance affecting individuals "environmental" behavior including:

institutional environment ("rules of the game") - that is the distribution of rights between individuals, groups, communities, and generations, and the system(s) of enforcement of these rights. Diverse rights could be defined by formal and/or informal rules (laws, tradition, culture, religion, ideological and ethical norms), and enforced by the state, convention, community pressure, trust, or self-enforcement; 
- $\quad$ market modes - those are various decentralized initiatives governed by the free market price movements and market competition (e.g. production and trade of organic products and origins, system of fair-trade etc.);

private modes ("private order") - those are diverse private initiatives, and specially designed contractual and organizational arrangements governing bilateral or multilateral relationships between private agents (e.g. voluntary individual or collective actions, codes of professional behavior, environmental contracts, eco cooperatives etc.);

- $\quad$ public modes ("public order") - these are various forms of a third-party public (Government, community, international) intervention in market and private sectors such as public regulation, taxation, public assistance, public funding, public provision etc;

- $\quad$ hybrid forms - some mixture combining features of market and/or private and/or public governance (e.g. state certifies organic producers and enforces organic standards and thus intensifies development of organic markets).

Generally organization of (any) environmental activity could be managed through a variety of alternative modes. For instance, "supply of environmental preservation service" could be a part of the main activity or a specialized activity of a farm and governed as: a voluntary activity of a farmer; though private contracts of the farmer with interested or affected agents; though interlinked contract between farmer and a supplier/buyer; though a cooperation (collective action) with other farmers and agents; though a (free) market or assisted by a third party (certifying and controlling agent) trade with special eco-products; though a public eco-contract specifying farmer's obligations and compensation; though a public order (regulation, taxation, quota); within a hierarchical public agency, or by a hybrid form. Furthermore, such actions could be carried out as a charity, non-for-profit, profit-making, or compulsory (mandated by the state or another authority) activity.

Efficiency of various governing modes is quite different since they have unlike comparative advantages and command different costs. Free market has big coordination and incentive advantages ("invisible hand", "power of competition"), and provides "unlimited" opportunities to benefit from specialization and exchange. However, market governance could be associated with high costs (risks) due to the big uncertainty, great possibility of opportunistic behavior, high unilateral dependency of assets, and/or low appropriability of certain rights. The special contract form permits better coordination, safeguard of investment, and intensification of exchange. However, it may require significant costs for specification of contract provisions, adjustments with constant changes in conditions, enforcement and disputing of negotiated terms etc. The internal (ownership) organization allows a greater flexibility and control of activity (direct coordination, adaptation, enforcement, and dispute resolution by a fiat). However, mitigation of most environmental problems requires extension of internal mode beyond family boundaries, and that usually commands significant costs for initiation, development, and current management (collective decision making, control of opportunism of the members of coalition, supervision and motivation of hired labor etc.).

Thus we have to access the specific coordinating, stimulating, enforcing etc. features of each governing mode taking into account related transaction costs. The positive transaction costs are associated with any form of governance and represent the costs for protection and exchange of property rights. If property rights were well-defined and transaction costs were zero then an effective environmental management would be done through any form of governance - free market, private organization, collective decision making, or a nationwide hierarchy (single private or state company). Then basic environmental rights would be easily protected and all information for optimization of 
resources (new eco-demand, available technologies etc.) costlessly obtained. In such a situation individuals would costlessly exchange (trade) rights they posses in their mutual benefit until exhausting the potential for sustainable development (maximum growth in productivity, maximum conservation and improvement of environment etc.). However, when property rights are not well defined and/or transaction costs are significant, then the specific structure of (environmental) management is crucial for the effective allocation of resources. Accordingly the comparative institutional analysis becomes an important tool for understanding and improvement of dominating system of governance.

Defining the comparative level of transaction costs is a key for accessing the efficiency (potential, limits) of different modes of governance. The rational economic agents will tend to use and/or invent such mode(s) of governance of their activities which is the most efficient in the specific institutional, economic and natural environment, and have the lowest costs comparing to all feasible alternatives (Williamson, 1996). The analysis is to focus on the comparative potential of available governing modes to economize on total (production and transaction) costs as well as identification of critical factors of transaction costs institutional, behavioral (agents bounded rationally, tendency for opportunism, risk aversion), dimensional (frequency, uncertainty, assets specificity, and appropriability of transactions), technological etc. Furthermore, the dominating ("efficient") modes of governing of agrarian activities will contribute to a different extend to sustainable (including environmental) development (Bachev, 2004). Therefore, any deficiencies in that respect are to be identified.

Persistence of serious environmental problems is a credible indicator that an effective system of environmental governance is not put in place. It shows that needed environmental preservation activity is not carried at effective (socially desirable) scale ${ }^{2}$. That is why a first step in the analysis and the improvement of environmental management is the identification of existing environmental problems and risks (Figure 1). Modern science offers very precise methods both to:

- detect various environmental problems and risks associated with agriculture, and

- improve farming practices in order to mitigate environmental hazards caused by agriculture and other (man-made or natural) factors.

Secondly, we have to identify the spectrum of specific (market, private, public and hybrid) modes of governance employed in farming, and access the extend they are contributing to effective environmental management, and identify the major institutional, behavioral, transaction costs etc. factors for their "eco-failures". At this stage we also have to estimate the potential of existing and other feasible governing structures to deal with emerging environmental problems and risks.

Next, serious deficiencies in dominating (market, private, public) structures to solve existing and emerging environmental problems (risks) are to be specified, and the needs for (new) public intervention to improve environmental management identified. For instance, market forms (such as organic farming) or private initiatives (eco-contracts and eco-cooperatives) may need a long time to emerge and/or may never solve the environmental problem. A public intervention could be much more efficient - e.g. introduction of mandatory regulation (limits, ban, methods and timing of application) on chemical use in farming could prevent soil, water and air contamination and preserve biodiversity.

\footnotetext{
${ }^{2}$ The social needs (demand) for environmental conservation and improvment are quite specific for each society and depend on the extend of envirenmental challanges, economic prosperity, tradition, progress in knowledge and perception, changes in culture etc.
} 
Figure 1: Steps in analysis and improvement of environmental management

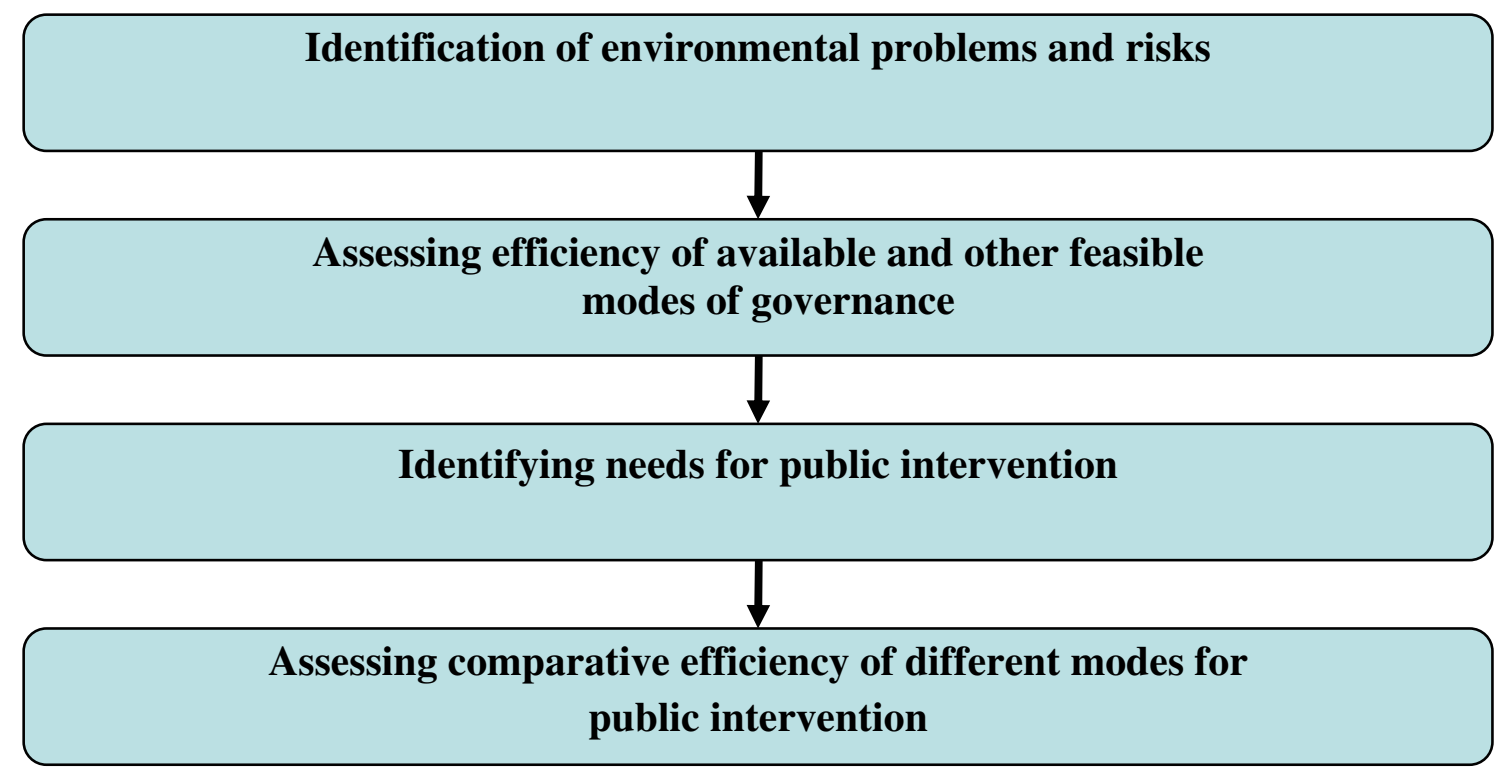

Finally, feasible modes of public involvement in environmental management have to be identified, their comparative efficiency assessed in terms of contribution to sustainable development and minimization of transaction costs, and the most efficient one(s) selected.

Very often market and private sector failures are caused by unspecified or badly specified private rights (low appropriability, public "over-regulation"). In such cases the most effective government intervention would be a fundamental institutional modernization introduction and enforcement of new private property rights (rights on natural, biological, and environmental resources; tradable quotas for polluting; private rights on intellectual agrarian property, organic and protected origin products etc.). The later would induce market and private incentives (and governance), and carry out certain environmental activities effectively.

In other instances, it would be more efficient to put in place regulations for trade and utilization of resources and products - standards for product quality, eco performance, animal welfare; norms for using natural resources, GM crops, and (water, soil, air, comfort) contamination; ban on application of certain chemicals or technologies; mandatory training and licensing of farm operators etc.

Sometimes, using the incentives and restrictions of tax system would be the most effective form for intervention. For instance, environmental taxation on emissions or products (inputs or outputs of production) is broadly applied to reduce use of harmful substances. In other cases, public assistance to private organizations is the best mode for intervention, and public funding (subsidies) for environmental actions is most commonly used instrument for improving eco-performance of farms.

Often providing public information, recommendations, training and education to farmers, other agrarian agents, and consumers are the most efficient. In some cases, pure public organization (in-house production, public provision) will be the most effective as it is 
in the case of agrarian research and education, agro-market information, agro-meteorological forecasts, border sanitary and veterinary control etc.

Usually individual modes are effective if they are applied alone with other modes of public intervention. The necessity of a combined intervention (governance mix) is caused by the complementarities (joint effect) of different forms; possibility to get an extra benefits (e.g. "cross-compliance" requirement for participation in support programs); particularity of environmental problems to be tackle; specific critical dimensions of governed activities; uncertainty (little knowledge, experience) associated with the impact of new forms; administrative capability of the Government to organize and finance different modes; and not least important the dominating (right, left) policy doctrine.

Besides, the level of effective public intervention (governance) depends on the kind of environmental problem and risk. There are public involvements which are to be executed at local (community, regional) level, while other requires nationwide governance. Additionally there are eco-activities, which are to be initiated and coordinated at international (regional, European Union, worldwide) level due to the strong necessity for trans-border actions (needs for cooperation in environment resources management, exploration of economies of scale/scope, governing of spill-overs) ${ }^{3}$ or consistent (national, local) government failures. Very frequently an effective environmental management requires multilevel governance with system of combined actions at various levels involving a diverse range of actors.

At this final stage our comparative institutional analyses also let us predict likely cases of public failures due to impossibility to mobilize sufficient political support and necessary resources and/or ineffective implementation of "good" environmental policies. Since public failure is a feasible option its timely detection permits foreseeing the persistence/rising of certain environmental problems and informing public about associated risks.

\section{Identification of Environmental Problems and Risks in Bulgarian Agriculture}

The post-communist transformation of Bulgarian agriculture has changed significantly the state of the environmental situation and brought to life a number of new challenges.

Total amount of used chemical fertilizers and pesticides has declined considerably (Figure 2). Comparing to 1989 the application of fertilizers and pesticides per hectare now represents merely $22 \%$ and $31 \%$ respectively. That sharp reduction in chemical use has diminished drastically the risk of chemical contamination of soils, waters, and farm produce ${ }^{4}$.

However, a negative rate of fertilizer application of $\mathrm{N}, \mathrm{P}$ and $\mathrm{K}$ intakes dominates being particularly low for phosphorus and potassium (Figure 3). Consequently, an average of 23595.4 t N, 61033.3 t P205 and 184392 t K20 have been irreversibly removed annually from soils since 1990. Furthermore, an unbalance of nutrient components has been typical with application of 5.3 times less phosphorus and 6.7 times less potassium with appropriate

\footnotetext{
${ }^{3}$ Recent epidemic of avian infection is a good example in that respect.

${ }^{4}$ Intensity of usage of chemicals per ha in Bulgaria ranks among the lowests in Europe with an average annual level for the last 10 years of $30.6 \mathrm{~kg} \mathrm{~N}, 3.6 \mathrm{~kg} \mathrm{P} 205,0.6 \mathrm{~kg} \mathrm{~K} 20,49.8 \mathrm{~kg}$ pesticides (including $25.6 \mathrm{~kg}$ herbicides).
} 
rate for the nitrogen used during that period. Moreover, a monoculture or simple rotation has been constantly practiced by most large farm managers concentrating on few profitable crops (such as sunflower and wheat). All these practices further contributed to deterioration of soil quality and soil organic matter content in the country.

Figure 2: Use of chemicals and irrigation in Bulgarian agriculture

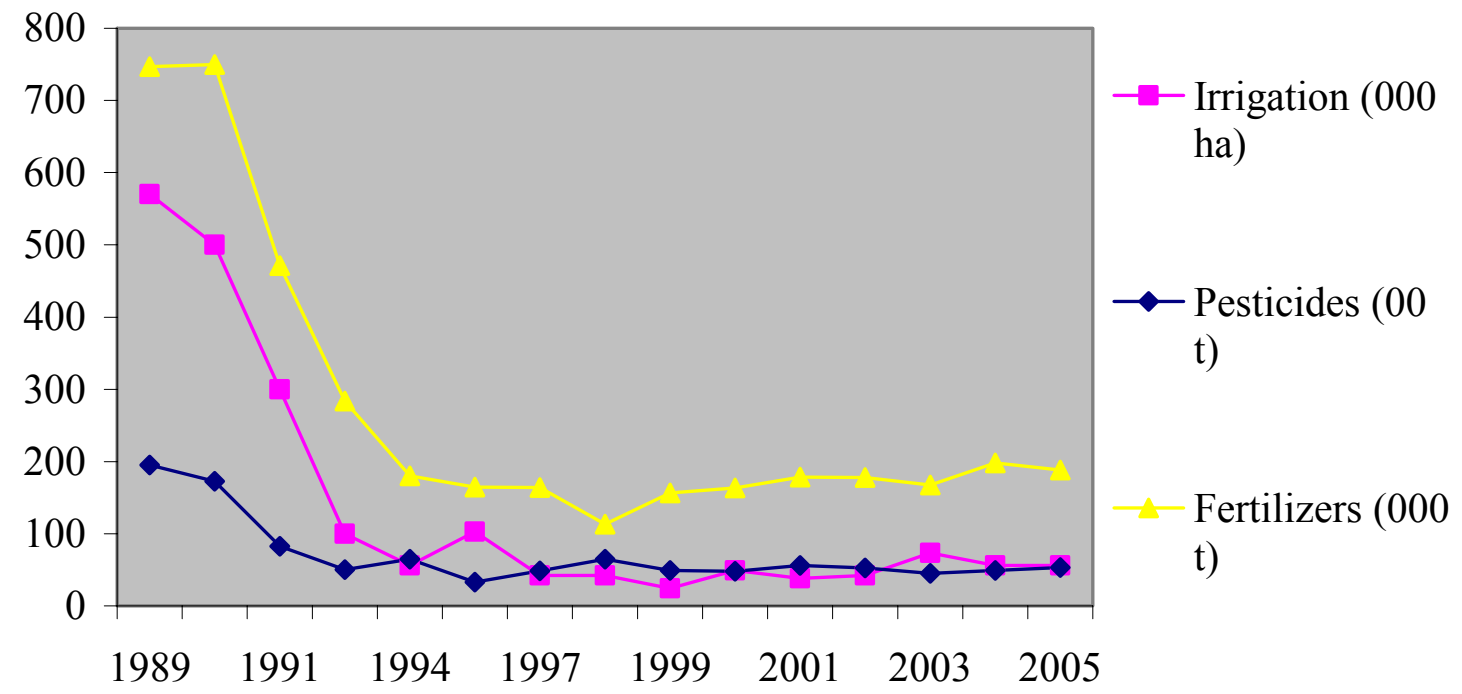

Sourse: National Statistical Institute

Figure 3: Rate of fertilizer compensation of basic elements in Bulgarian agriculture.

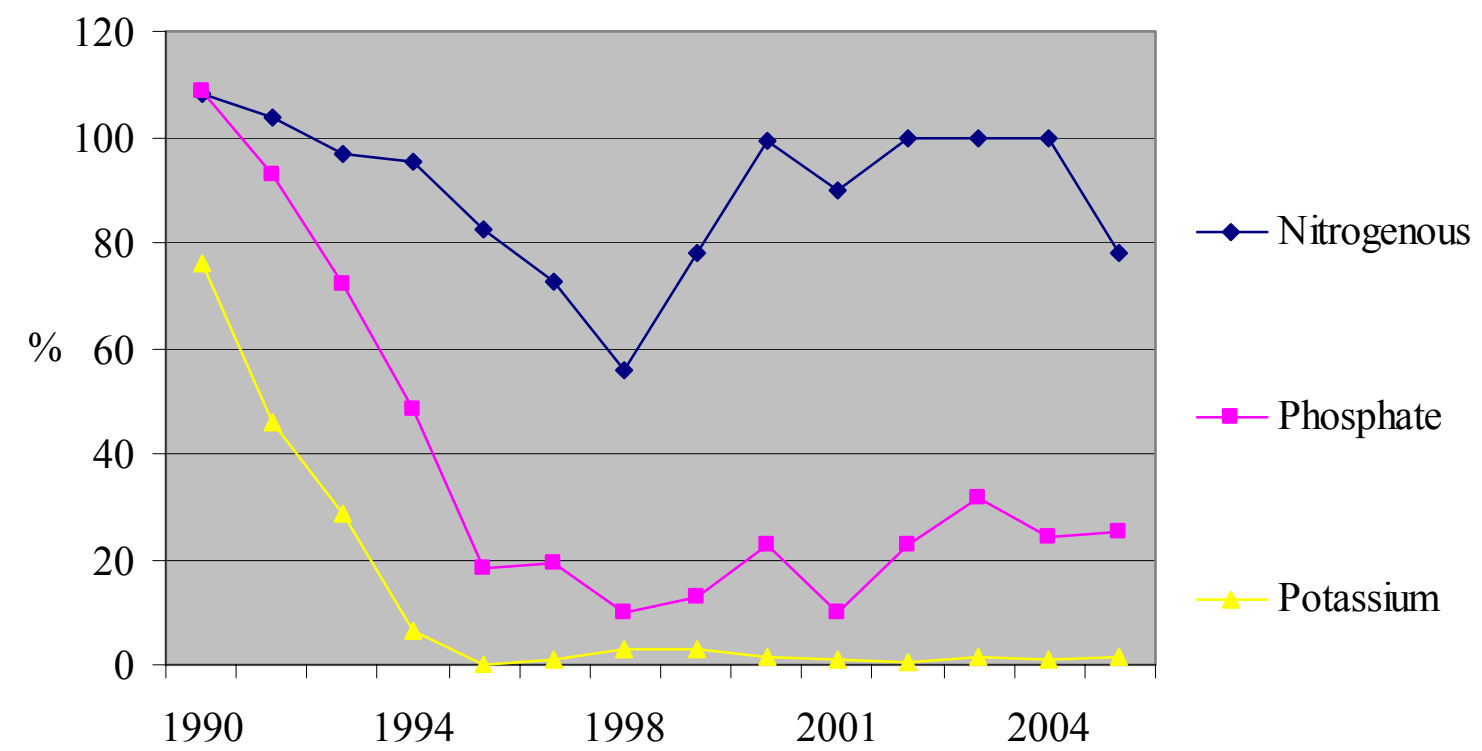

Source: Ministry of Agriculture and Forestry 
There has been considerable increase in agricultural land affected by acidification in the country (Figure 4). Soil acidification occurs as a result of a long-term application of specified nitrate fertilizers ${ }^{5}$ and unbalanced fertilizer application without adequate input of phosphorus and potassium. Currently almost $25 \%$ of soils are acidified as percentage of degraded farmland acidified soils reach $4.5 \%$ of total lands. After 1994 the percentage of acidified soil began to decrease, however, in recent years there is a reverse tendency along with the gradual augmentation of use of nitrates. The fraction of salt affected land has doubled after 1989 but it is still an insignificant (mostly abandoned or intensively irrigated) part of the total farmland. During the entire period no effective measures have been taken to normalize soil acidity and salinity ${ }^{6}$.

Figure 4: Share of degradated agricultural lands in Bulgaria

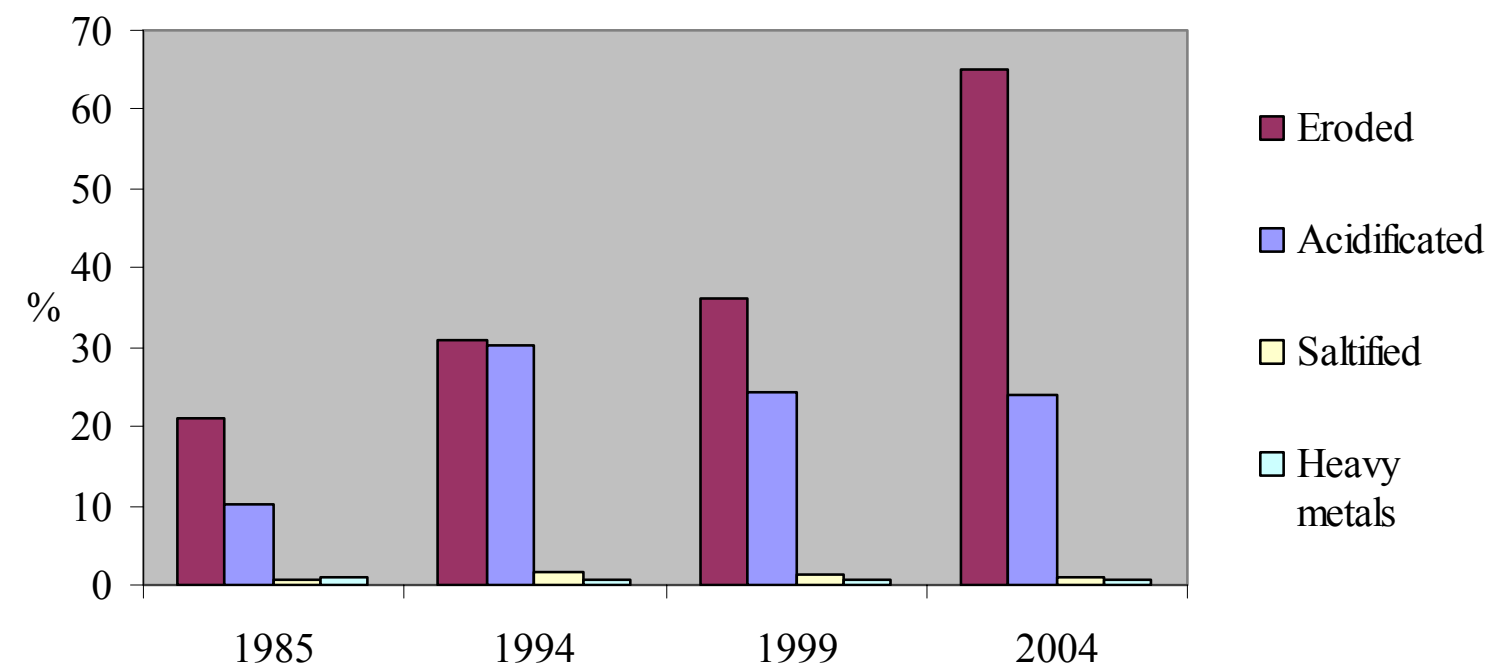

Source: Executive Environment Agency

Erosion has been a major factor for land degradation in the country (Figure 4). Around one-third of the arable lands are subjected to wind erosion and $70 \%$ to water erosion ${ }^{7}$. Soil erosion intensity and scope depend on topographic attributes, soil type, and climate factors (intensity of rainfalls, frequency of dust storms). Since 1990 water and wind erosion affect between $25-65 \%$ of farmland and total losses varies from 0.2 to $40 \mathrm{t} / \mathrm{ha}$ in different years (EEA). Annual losses of earth masses from water erosion are estimated at $136 \mathrm{Mt}$ while wind erosion deflates between 30-60 $\mathrm{Mt}^{8}$. The progressing level of erosion is a result of the extreme weather but it has been also adversely affected by dominant agro-techniques, deficiency of anti-erosion measures, and uncontrolled deforestation.

\footnotetext{
${ }^{5}$ Consisting mostly of ammonium nitrate (70-80\%) and carbamide (20-30\%) (EEA).

${ }^{6}$ For instance, limed acidificated lands comprses far bellow $2 \%$ of the areas limed until 1990. And no cemical melioration or drainage of salinified land has been effectively implemented (MAF).

${ }^{7}$ All terrains with a slope over 20 degree are affected by water erosion. There is a risk of erosion of more than $5 \mathrm{t} / \mathrm{ha} / \mathrm{y}$ for over a quarter of arable lands (including $65 \%$ of orchards and vineyards) (EEA, 2006).

${ }^{8}$ Two-third of water erosion losses and almost all of wind erosion losses come from the arable land (EEA).
} 
Irrigation impact on erosion and salinization has been significantly diminished after 1990. There has been a sharp reduction of irrigated farmland (Figure 2) as merely $2-4.7 \%$ of existing irrigation network has been practically used. Moreover, a considerable physical distortion of irrigation facilities has taken place affecting $80 \%$ of the internal canals (MAF). The harmful effect of the later has been combined with a fall of rainfalls in recent years and shortage of irrigation water in reservoirs. The decline in irrigation has had a direct negative effect on crop yields and structure of the crop rotation. In addition, irrigation has not been effectively used to counterbalance the effect of global worming on farming (extension of farm season and increased water requirements) and further degradation of agricultural land. Bulgarian farming has not been adapted to cope with new environmental challenges caused by the alteration of extreme drought and rainstorms, increased risk of dry winds and reduction of rainfalls, and unfavorable modifications in soils quality.

The areas of agricultural land industrially polluted by heavy metals generated by industrial wastes have fallen after 1990 (Figure 3), they are not significant, and only about $30 \%$ of the affected soils need special monitoring. However, pollution of soil and water from industrial activities, waste management, and inproper farming activities present risk for the environment and human health. Data shows that in $6.6 \%$ of the tested soils, concentration of pollutants is higher than the contamination critical limits (EEA, 2006).

Around a quarter of the riverlength does not meet the normal standards for good water quality (MAF, 2006). The nitrates content in ground water have been decreasing, and now only $0.7 \%$ of samples exceed the ecological limit value of $10 \mathrm{mg} / \mathrm{l}$ (EEA, 2006). Nevertheless, monitoring of water for irrigation shows that in $45 \%$ of water samples, the nitrates concentration exceeds the contamination limit value by 2 to 20 folds (MAF, 2006). Nitrates are also the most common polluter of underground water - for the last 5 years with a slight excess over the ecological limit (EEA, 2006). Recently defined Nitrate Vulnerable Zones (2004) cover $60 \%$ of the territory of the country and less than $7 \%$ of agricultural land use. The lack of effective manure storage capacities and sewer systems in majority of farms contribute significantly to the persistence of the problem. According to the last census merely $0.1 \%$ of the livestock farms possess safe manure-pile sites, around $81 \%$ of them use primitive dunghills, and as many as 116 thousands holdings have no facilities at all (MAF, 2003). A major part of the post-communist livestock practices are carried out by a great number of miniature (small) and primitive holdings often located within village and town borders. It contributes significantly to pollution of air, water and soils, and disturbing population comfort (unpleasant noise and odor, dirty roads etc.).

A serious environmental challenge has been caused by the deficiency in storing and disposal of the out-of-dated or prohibited pesticides of the ancient public farms. Currently those chemicals account for $11079 \mathrm{t}$ and a good proportion of them are not stored in safe places. As much as $82 \%$ of all polluted localities in the country are associated with these dangerous chemicals, and only a tiny portion of them have gone through the entire cycle of examination (EEA, 2006). There are registered 477 abandoned storehouses for such pesticides, situating in 460 locations around the country, and just 38\% of them are guarded. In addition, there has been reported general levels of pollutants exceeding the ecological limit value for triasine pesticides in underground water through the last 5 years which is a consequence of the increased use of these chemicals. Above and beyond, the illegal garbage yards in rural areas have noticeably increased ${ }^{9}$. Farms contribute extensively to waste

${ }^{9}$ Official figure for major illegal garbage locations is 4000 (EEA). 
"production" with both organic and industrial materials, leading not only to negative changes in the beauty of scenery but also bring about air, soil and water pollution.

There have been significant degrading impacts of agriculture on biodiversity in the country. The policy toward intensification and introduction of foreign varieties and breeds during communist period, and the lack of any policy toward protection of biodiversity afterwards have led to degradation of the rich diversity of local plants and animal breeds. According to the official data all 37 typical animal breeds in Bulgaria have been endangered during the last several decades as 6 among them are irreversibly extinct, 12 are almost extinct, 16 are endangered and 3 are potentially endangered (MEW, 2006).

Moreover, since 1990 a considerable portion of agricultural lands have been left uncultivated for a long period of time or entirely abandoned ${ }^{10}$. The later has caused uncontrolled "development" of species allowing development of some of them and suppressing others. Besides, some of the most valuable ecosystems (such as permanent natural and semi-natural grassland) have been severely damaged ${ }^{11}$. Part of the meadows has been left under-grazed or under mowed, and intrusion of shrubs and trees into the grassland took places. Some of fertile semi-natural grasslands have been converted to cultivation of crops, vineyards or orchards. This has resulted in irreversible disappearance of plant species diversity. Meanwhile, certain public (municipal, state) pastures have been degraded by the unsustainable use (over-grazing) by private and domestic animals. In addition, a reckless collection of some valuable wild plants (berries, herbs, flowers) and animals (snail, snakes, fish) have led to destruction of all natural habitats. Above and beyond, some genetically modified crops have been introduced without an independent assessment (studies) of possible hazards for traditional and organic production (genetic pollution) and human health, or providing appropriate safeguards or proper public and consumer information.

There has been a significant reduction of overall green-house gas (GHG) emissions from agriculture since 1988 (Figure 5). Moreover, the decline in the sector's contribution has been higher than the national. After 2000 there is a reverse trend toward a general increase in the total national emissions GHG, and GHG from agriculture ${ }^{12}$ as well. In 2001-2004 agriculture released $1.8 \%$ of Nox, $9 \%$ of NMVOC, $16.9 \%$ of $\mathrm{CH}_{4}, 67.6 \%$ of $\mathrm{NH}_{3}$, and $0.2 \%$ of $\mathrm{CO}$ in the country (EEA, 2005).

${ }^{10}$ Currently, fallow land accounts for $13.4 \%$ of arable land and uncultivated (for more than 3 years) farmland comprises $7.9 \%$ of all agricultural land (MAF, 2006). In some post-communist years of transition abandoned land reached up to $35 \%$ of total agricultural land.

${ }^{11}$ The permanent grasslands (mostly seminatural) comprise more than a third of Utilized Agricultural Land in the country (MAF, 2006). Approximately $20 \%$ of the agricultural lands of Bulgaria are lands of High Nature Value according to the definition of the European Agency on Environment (MAF).

${ }^{12}$ GHG emissions from "Sector Agriculture" account for activities during the production and processing of agricultural products, soil fertilization and animal manure processing and preservation. All emissions from combustion processes for energy production and from agricultural machines are reported in the "Energy sector" but they represent insignificant amount (EEA). 
Figure 5: Trend and components of green-house gas emissions from Bulgarian agriculture

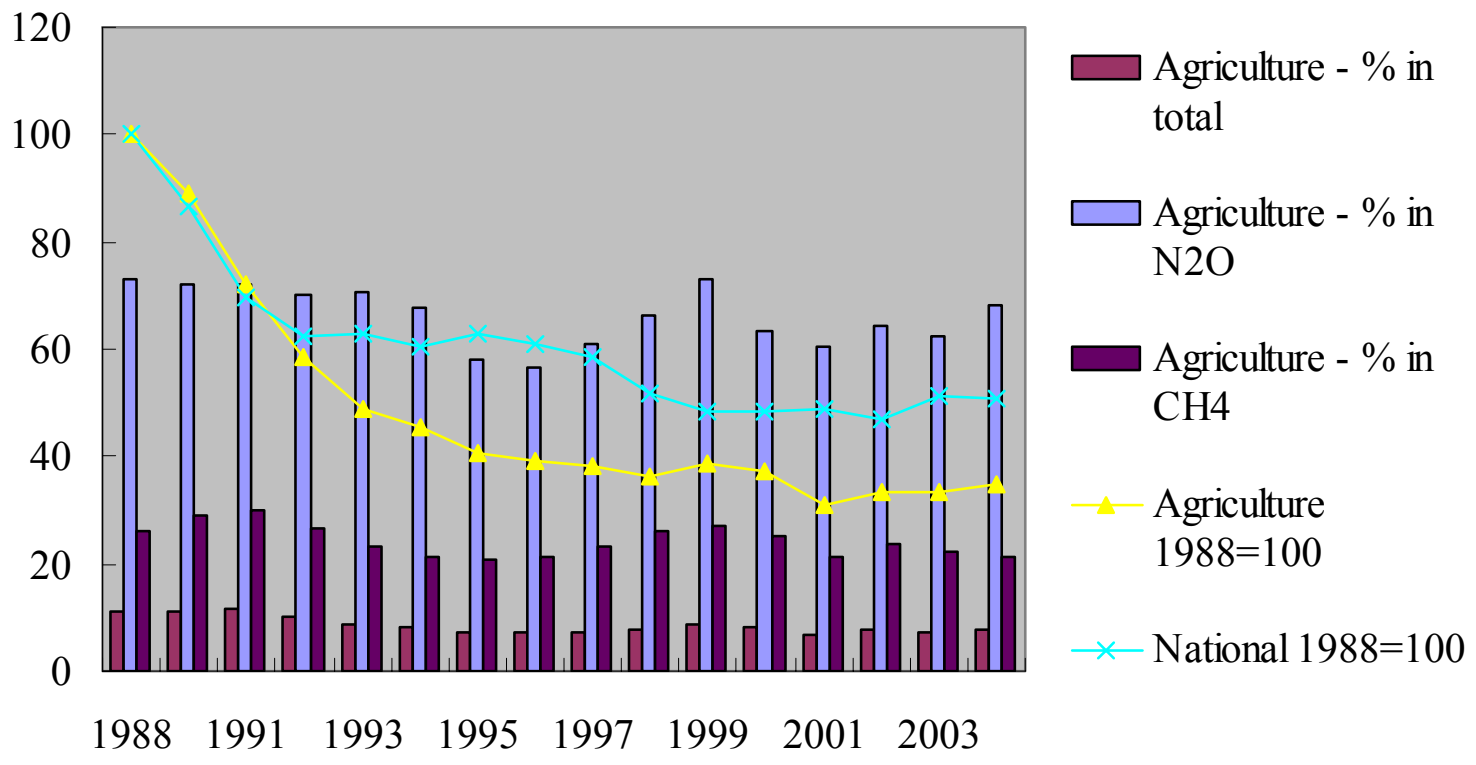

Source: Vassilev et al., 2006

The $\mathrm{N}_{2} \mathrm{O}$ emissions comprise $57.4 \%$ of the total emissions from agriculture (in $\mathrm{CO} 2$ equivalent) and there is a slight enlargement of the share in last 5 years. Agriculture has been a major ammonia source accounting for two-third of the national emission. After 2000, the majority of $\mathrm{NO}_{2}$ emissions come from agricultural soils $(86.7 \%)$ and manure management $(13.2 \%)$.

The methane emission from agriculture represents about $25 \%$ of the national. After 2000 the biggest portion of $\mathrm{CH}_{4}$ comes from fermentation from domestic livestock $(72.5 \%)$ and manure management $(24.2 \%)$. There is a four-fold increase of $\mathrm{CH} 4$ from rice cultivation since 1999 as a result of development of this farming sector. The share of GHGs from field burning of residues and crops (which also emits GHGs-precursors) is not significant but it has doubled since the period before 1990.

All these figures show that Bulgarian agriculture creates significant environmental problems and poses considerable environmental risks which are to be effectively managed. In order to understand to what extend existing governing structures could deal with present environmental challenges we have to analyze their effective potential for environmental management.

\section{Efficiency of Market, Private and Public Modes of Environmental Management}

Since 1989 Bulgarian agriculture has seen a fundamental transformation of the property rights and institutional structures (Bachev and Tsuji; Bachev and Kagatsume, 2002a). New private rights on major natural (farmland, forestry, water etc.) resources has been introduced or restored, markets and trade have been liberalized, modern public support and regulations have been introduced. 
During most of the transition diverse environmental rights (on clean and athetie nature; preservation of natural resources, biodiversity etc.) were not defined or were badly defined and enforced (Bachev, 2007b). Out-dated system of public regulations and control dominated until recently which corresponded little to contemporary needs of environmental management ${ }^{13}$. Besides, there was no modern system for monitoring the state of soil, water, and air quality, and credible information on the extent of environmental pollution and degradation was not available. Furthermore, there existed neither social awareness of the "concept" of sustainable development nor any "needs" to be included in public policy and/or private and community agenda. The lack of culture and knowledge of sustainability has also impeded evolution of voluntary measures, and private and collective actions (institutions) for effective environmental management.

In the last few years before EU accession, country's laws and standards were harmonized with the immense EU legislation ${ }^{14}$. Community acquis have introduced a modern framework for the environmental governance including new rights (restrictions) on protection and improvement of environment, preservation of traditional varieties and breeds, biodiversity, animal welfare etc. However, a good part of these new "rules of the game" are not well-known or clearly understood by the various public authorities, private organizations and individuals. Generally, there is not enough readiness for effective implementation of the new public order because of the lack of experience in agents, adequate administrative capacity, and/or practical possibility for enforcement of novel norms (lack of comprehension, deficient court system, widespread corruption etc.). In many instance, the enforcement of environmental standards is difficult (practically impossible) since the costs for detection and penalizing of offenders are very high, or there is no direct links between the performance and the environmental impact. For example, although the burning of (stubble) fields has been banned for many years since it is harmful for the environment yet this practice is still widespread in the country.

The harmonization with the EU legislation and the emergence of environmental organizations also generate new conflicts between private, collective and public interests. However, the results of public choices are not always for the advantage of effective environmental management. For instance, the strong lobbying efforts and profit-making interests of particular individuals (and groups) have led to $20 \%$ reduction in numbers and $50 \%$ reduction in area of initially identified sites for the pan European network for preservation of wild flora, fauna and birds NATURA 2000.

During much of the transition newly evolving market, private and hybrid structures have not been efficient in dealing with various environmental issues.

Privatization of agricultural land and other non-land assets of ancient public farms took almost 10 years to complete ${ }^{15}$. During a good part of that period, the governance of critical agrarian resource was in ineffective and "temporary" structures (such as Privatization Boards, Liquidation Councils, Land Commissions etc.). Sales and long-term lease markets

\footnotetext{
${ }^{13} \mathrm{Bad}$ enforcement of laws and absolute and contracted rights is common in Bulgaria. Requirements for fighting against corruption and reforming administration and juridical system are underlined by the Monitoring Report for the Preparation for EU Membership (EU 2006) and closely scrutinized by the EC after accession.

14 Acquis Communitaire which was adapted before the accession of Bulgaria to EU (January 1, 2007) contains 26000 pieces of legislation accounting for 80000 pages.

${ }^{15}$ Until 1989 farming in Bulgaria was carried in few number of large public farms avaraging tens of thousands of ha. Besides, there were more than a million small "personal plots" (farms).
} 
for farmland did not emerge until 2000, and leasing on an annual base was a major form for the extension of farm size until recently. That was combined with a high economic uncertainty and a big inter-dependency of agrarian assets (Bachev, 2006). Consequently, most of farming activities has been carried out in less efficient and unsustainable structures such as part-time and subsistence farms, production cooperatives, and huge business farms based on provisional lease-in contracts (Table 1). Specialized livestock farms comprise a tiny portion of all farms (mostly in poultry and swine) while $97 \%$ of the livestock holdings are miniature "unprofessional farms" breading $96 \%$ of the goats, $86 \%$ of the sheep, $78 \%$ of the cattle, and $60 \%$ of the pigs in the country (MAF, 2005). Furthermore, market adjustment and intensifying competition has been associated with a significant decrease in unregistered farms by $71 \%$ and the cooperatives by $42 \%$ since 1995 .

Table 1. Number, size and importance of different type farms in Bulgaria

\begin{tabular}{ccccc}
\hline & Unregistered & Cooperatives & Agro-firms & Total \\
\hline Number & & & & \\
1995 & 1772000 & 2623 & 2200 & 1777000 \\
2000 & 755300 & 3125 & 2275 & 760700 \\
2005 & 515300 & 1525 & 3704 & 520529 \\
\hline Share in number (\%) & & & & \\
1995 & 99.7 & 0.1 & 0.1 & 100 \\
2000 & 99.3 & 0.4 & 0.3 & 100 \\
2005 & 99.0 & 0.3 & 0.7 & 100 \\
\hline Share in farmland (\%) & & & & \\
1995 & 46.5 & 40.7 & 12.8 & 100 \\
2000 & 19.7 & 61.6 & 18.7 & 100 \\
2005 & 33.5 & 32.6 & 33.8 & 100 \\
\hline Average size (ha) & & & & \\
1995 & 1.3 & 800.0 & 300.0 & 2.8 \\
2000 & 0.9 & 709.9 & 296.7 & 4.7 \\
2005 & 1.8 & 584.1 & 249.4 & 5.2 \\
\hline
\end{tabular}

Source: Ministry of Agriculture and Forestry

Dominating modes for carrying out farming activities have had little incentives for long-term investment to enhance productivity and environmental performance (Bachev, 2006). The cooperative's big membership makes individual and collective control on management very difficult (costly). That focuses managerial efforts on current indicators, and gives a great possibility for using coops in the best private interests. Besides, there are differences in investment preferences of diverse members due to non-tradable nature of the cooperative shares ("horizon problem"). Given the fact that most members are small shareholders, older in age, and non-permanent employees, the incentives for long-term investment for land improvement and renovation of material and biological assets have been very low. Last but not least important, "member-oriented" (non-for-profit) nature of coops prevents them to adapt to diversified needs of members and markets (demand, competition). 
On the other hand, small-scale and subsistent farms ${ }^{16}$ possess insignificant internal capacity for investment, and small potential to explore economy of scale and scope (big fragmentation and inadequate scale). Besides, they have little incentives for non-productive (e.g. eco-, animal welfare etc.) investment. Moreover, there has been no administrative capacity and political will to enforce quality and eco-standards in that vast informal sector of the economy.

Likewise, the larger business farms operate mainly on leased land and concentrate on high pay-off investment with a short pay-back period. That has been coupled with ineffective outside pressure (by authority, community) for respecting official standards for ecology, land use (e.g. crop rotation. nutrition compensation), biodiversity etc. In general, survivor tactics and behavior rather than a long-term strategy toward farm sustainability has been common among the commercial farms.

Furthermore, during the entire transition phase the agrarian long-term credit market was practically blocked due to the big institutional and market uncertainty, and the high specificity of much of the farm investments (Bachev and Kagatsume, 2002b). In addition, newly evolving Bulgarian farming has been left as one of the least supported in Europe ${ }^{17}$. Until 2000 the public aid was mainly in the form of preferential short-term credit for the grain producers and insignificant support to capital investments. That policy additionally contributed to the destructive impact for unbalanced unilateral $\mathrm{N}$ fertilization by the biggest producers having access to the programs. Despite the considerable progress in the public support since 2000 (most of which comes from EU Special Assistance Program for Agriculture and Rural Development) the overall support to agriculture is considered very little (Bachev and Kagatsume, 2005). In addition, only a small proportion of the farms benefits from some form of public assistance most of these farms being large enterprises from regions with less socio-economic and environmental problems. Basically, a publicly supported farm must meet the requirements for good environmental performance. However, the minor amount of actually supported farms, and the deficiency of clear criteria for eco-performance, and the lack of effective control, have contributed barely to overall improvement of environmental situation in the country. Which is more, envisaged Special Accession Program for Agriculture and Rural Development measure "Agro-ecology" was not approved until the middle of 2006 and projects are funded under that scheme since 2007

Hence, since 1990 all "environmental management" has been left on farmers "good will" and "market signals". Market governance (competition, marginal rule) has led to a significant decline in most of crop and livestock productions (Figure 6). That has been due to the several folds interrelations between rise in agrarian inputs (chemicals, water, machinery etc.) and farm produce prices, drop in internal and export demands, and failure to adapt to new market environment by a great deal of farms (Bachev and Kagatsume, 2002a). The smaller size and owner operating nature of majority of farms avoided certain problems of large public enterprises from the past (e.g. lost natural landscape, biodiversity, nitrate and pesticide contamination, huge manure concentration, uncontrolled erosion etc.). Subsistent and small-scale farming has also revived some traditional (and more sustainable) technologies, varieties and products. A by-product from that "market and private

${ }^{16}$ Subsistence and semi-subsistence farms comprise the best part of the farms as almost 1 million Bulgarians are involved in farming mostly on a part-time base and for "supplementary" income (MAF, 2006).

${ }^{17}$ Estimates demonstrate that the Aggregate Level of Support to Agriculture before 2000 was very low, close to zero or even negative (OECD, 2000). 
governance" was a considerable desintensification of agriculture, and ease of general environmental pressure and generated pollution comparing to the pre-reform level. Consequently, a good part of the farm production got unintended organic character obtaining a good (internal and international) reputation for products with a high quality and safety. In additions, the private mode has introduced incentives and possibilities for an integral environmental management (including revival of eco- and cultural heritage, anti-pollution, esthetic, comfort etc. measures) profiting from the inter-dependent activities such as farming, fishing, agro-tourism and recreation, processing, trade etc.

\section{Figure 6: Dynamics of major crop and livestock productions in Bulgaria} (1989=100)

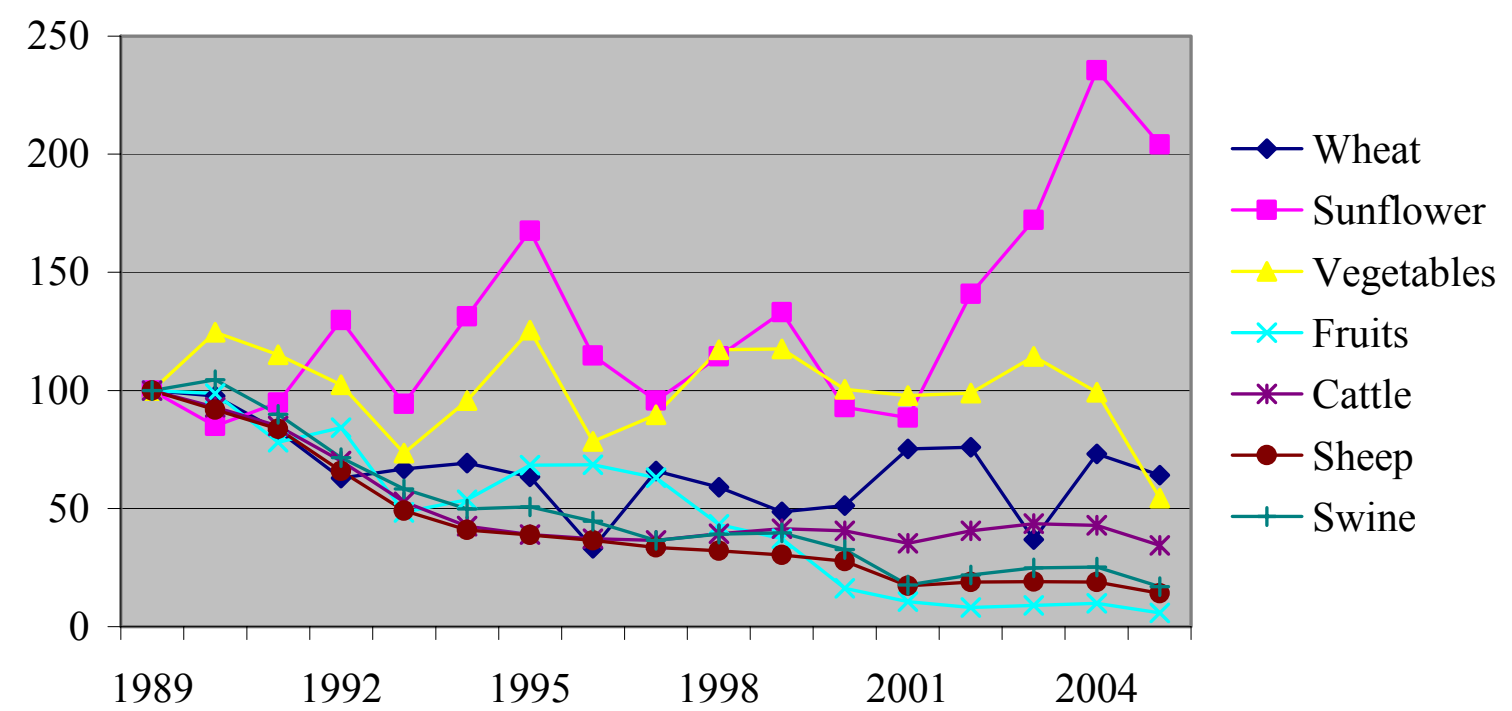

\section{Source: National Statistical Institute}

However, improved environmental stewardship to owned resources did not extend to the nature in general (low appropriability of rights). The private management has been often associated with less concern to the manure and garbage management, over-exploitation of leased and common resources, and contamination of air and groundwater. Basically, there is a considerable time and space gap for much of the environment related costs and benefits. Little appropriability of such transactions (associated with positive or negative externalities) can be hardly governed though a market or private mode and constant under-investment in positive externalities and over-production of negative externalities come to exist (Bachev, 2004; Bachev, 2007a). Subsequently, the adverse trend to further deterioration of soil quality (exhaustion, erosion, and acidification), distortion of eco-balance, and development of other environmental problems, have taken place.

A market driven organic farming has emerged in recent years as well (Figure 7). It is a fast growing approach but it is restricted to 92 farms and covers merely $0.23 \%$ of the Utilized Agricultural Area (MAF, 2006). In addition, 27881 ha has been approved for gathering wild organic fruits and herbs. There are also 5 organic livestock farms with 722 animals (cattle, sheep, and goats) and 269 bio-apiaries with 23883 bee families. The organic form has been introduced by business entrepreneurs who managed to organize and fund this 
new venture arranging needed independent certification (practically all certification is done by foreign certification bodies) and finding potential buyers for the highly specific output. Produced bio fruits, vegetables, essential oil plants, herbs, spices, and honey are entirely for export since only a tiny internal market for organic products exists in the country. The slow development of organic market is not only because of the higher prices of organic products but also because of the limited consumer confidence in the authentic character of products and certification ${ }^{18}$. In addition, eco-labeling of processed farm products (relying on self-regulation) have appeared which has been more a part of the marketing strategy of certain companies rather than a genuine action for environmental improvement.

Figure 7: Development of organic farming in Bulgaria

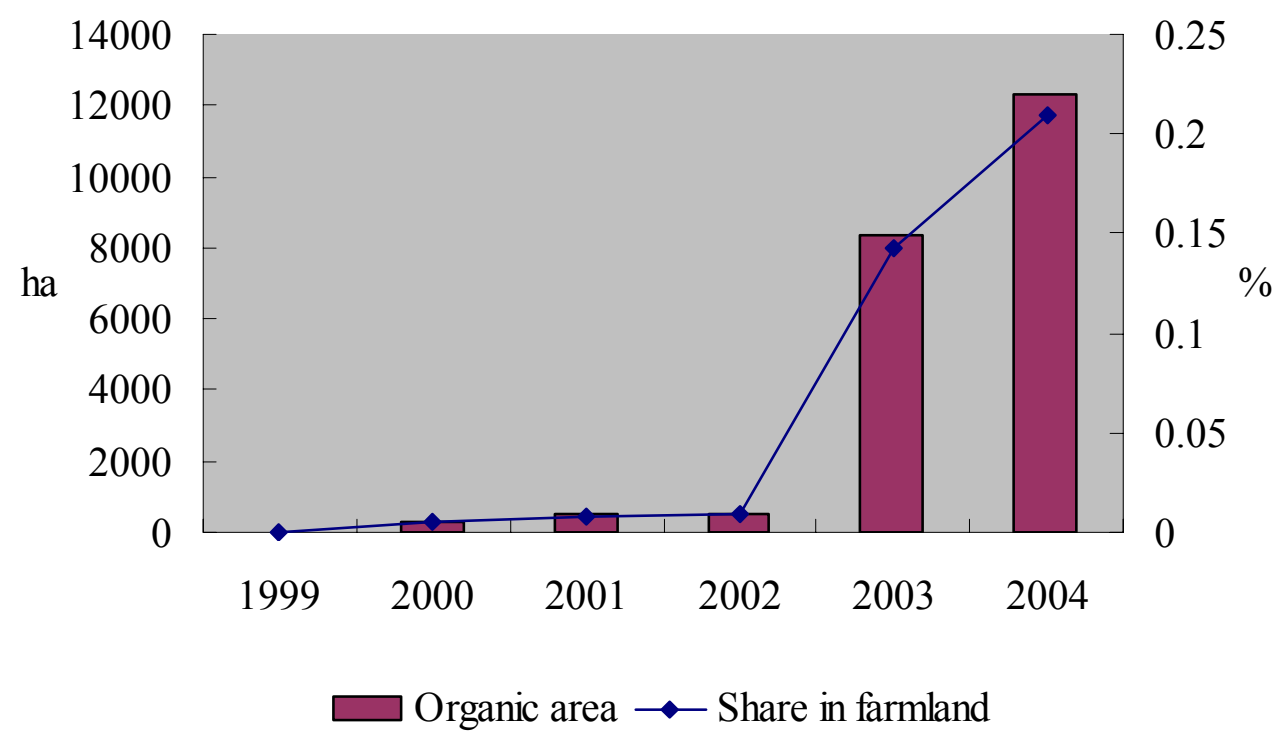

Source: Ministry of Agriculture and Forestry

Since 2001 the assets of public owned irrigation companies were transferred to the newly evolving Water Users Associations. However, expected "boom" in efficiency (quantity, productivity) from a collective management of irrigation activities have not been materialized. That is because of the semi-monopoly situation of regional state water suppliers (monopoly terms and pricing), little water-users incentives to innovate facilities and expand irrigation, and still uncompleted privatization of state irrigation assets.

Generally, an initiation, development and maintenance of an organization of large group is very costly, and such a coalition is not sustainable for a long time ("free rider" problem). In Bulgaria, the evolution of farmers and environmental associations has been additional hampered by the big number of rural agents and their diversified interests (size of ownership and operation, type of farming, individual preferences, different age and horizon etc.).

Market and private sector have failed to govern effectively the environment related activities in Bulgarian agriculture. There has been a need for a third-party public intervention

${ }^{18}$ A great number of fake labeling as organic of traditional products have been detected by the Organsiation for Consumer Protection and reported in media. 
(assistance, regulation, support, partnership, in house organization). However, the Government and local authority involvement has not been significant, comprehensive, sustainable, or even related to the matter (Bachev, 2007b). The total budget of the Ministry of Water and Environment accounts for just $1.5 \%$ of the National Budget, and a sizeable piece of it (more than 26\%) comes from the EU (MWE, 2006). Besides, the agricultural sector gets a tiny portion of all public eco-spending.

In the passed several years a number of programs have been developed to deal with the specific environmental challenges ${ }^{19}$. In addition, national monitoring systems of environment and biodiversity have been set up. Likewise, a mandatory ecological assessment of public programs was introduced in 2004. Nevertheless, the actual eco-policies rest fragmented and largely reactive to urgent environmental problems (natural disasters such floods, storms, drought) rather that based on a long-term strategy for sustainable development (Bachev, 2007). Moreover, there is no efficient coordination between different programs and management levels. The programs and action plans are usually developed and executed in a highly centralized manner (by bureaucrats, foreign experts, and profit-making companies) without involvement of independent local experts, stakeholders and pubic at large. In addition, there is considerable deficiency in administrative capacity at local level in terms of staff, qualification, material and financial means. As a result of all of these, inefficiency in priority setting and management (incompetence, corruption), and a minor impact of the public programs prevails.

More-over, a multifunctional role of farming has not been effectively recognized; and proper system for its assessment (data, indicators) introduced; and provision of a public service "environmental preservation and improvement" funded by the society. Neither, the essential public institutions and infrastructure crucial for the sustainable farming development have been built: public system for enforcement of laws, regulations, and contracts does not work well; essential property rights (on environmental resources and biodiversity, special and organic products, GM products and intellectual agrarian property) are not well defined and/or properly enforced; public support programs are rarely governed effectively and in the best interest of the legitimate beneficiaries; agricultural research is under-funded and can hardly perform its function for innovation and independent expertise; newly established agricultural advisory system does not serve the majority of farms and include environmental issues; urgently needed public system for agrarian insurance has not been introduced; crucial agrarian and rural infrastructure (wholesale markets, irrigation, roads, communications) has not been modernized; public support for initiating and developing farming associations has not been given etc.

A great number of international assistance projects (funded by the UN agencies, EU, Foreign Governments, NGOs etc.) have been carried out to "fill the gap" of the national government failures. They either focus on a specific issue (sustainable agriculture, desertification etc.) or mobilize local actors for sustainable development. These programs introduce western experiences in governance and try to make a difference. However, they are limited in scale and unsustainable in time; in some cases overtaken by the local groups and

${ }^{19}$ National Strategy for Preservation of Biodiversity (1999); National Strategy for Environment (2000); National Plan for Agrarian and Rural Development (2000), National Programme for Limitation of Total Emissions of Sulphur Dioxide, VOC, and Ammonia (2002); National Program for Waste Management Activities (2002); Environmental Strategy for the Instruments of ISPA (2003), National Strategy for Management and Development of Water Sector (2004); Strategy for Developing Organic Agriculture (2005) etc. 
funding improperly used; and above all with no significant impact. The endurance of environmental and other challenges demonstrates that an effective system of governance has not been put in place. Subsequently, the modernization of Bulgarian farms according to the EU (quality, safety, environmental, animal welfare etc.) standards has been delayed; and growth in farms productivity, competitiveness and sustainability severely restricted; and technological, income and eco-disparity between farms of different type, sub-sectors and regions broadened (Bachev and Kagatsume, 2005).

\section{Environmental Management in Conditions of EU CAP Implementation}

The EU integration and CAP implementation will provide new opportunities for Bulgarian farms (Bachev, 2007). The EU funding alone, which agriculture will receive from 2007 on, will be 5.1 times higher than the overall level of support to farming before acceding $^{20}$. Besides, the EU accession introduces and enforces a "new order" - strict regulations and control; tough through quality, food safety, environmental etc. standards; financial support and protection against market instability etc. The external monitoring, pressure and likely sanctions by the EU will lead to better enforcement of laws and standards in the country. For instance, in March 2007 the EC started a procedure for sanctions against Bulgaria for not reducing emissions of greenhouse gasses according to the EU Program for Environment and Combating Adverse Climate Changes.

Furthermore, huge EU markets will be opened which will enhance competition and let Bulgarian farms explore their comparative advantages (low costs; high quality, specificity and purity of produce etc.). The novel conditions of market competition and institutional restrictions will give strong incentives (pressure) for new investments for increasing productivity and conforming to higher product, technology and environmental standards. The larger and business farms are most sensitive to new market demand and institutional regulations since they largely benefit (or lose) from timely adaptation to new environmental regulations. Besides they have higher capacity to generate resources and find outside (credit, equity, public) funding to increase competitiveness and meet new institutional requirements. The process of adaptation will be associated with appropriate land management and the intensification of production. The later could revive or deepen some of the environmental problems (erosion, acidification, pollution) unless a pro-environmental governance (public order, regulation etc.) is put in place to prevent that from occurring. On the other hand, small-scale producers and most livestock farms will have a hard time adapting to new competition pressure, investment needs, and new food safety, environmental, animal-welfare etc. standards (Bachev, 2007b).

A significant part of the farms will be qualified to receive direct payments from EU. In view of the current (low) level of support, the direct payments will augment farm sustainability and give means for adaptation to the new standards. However, the EU support will benefit uneven different type of farms as no more than $3 \%$ of the farms (large farms, cooperatives, and agri-firms) will obtain more than $85 \%$ of the subsidies. Many effective

${ }^{20}$ For 2007-2009 the EU funds allocated for "agrarian and rural development", for "direct payments", and for "market support" accounts for $€ 733$ millions, 722 million, and $€ 388$ million accordingly. Besides, Bulgarian agriculture will receive resources from the EU Structural Funds and the national budget. 
small-scale operators (vegetables, tobacco, green-house) and subsistence farms will receive no or only a tiny fraction of the direct payments. Besides, specialized livestock farms will not be eligible to receive any payments under the "area based scheme". Above and beyond, the bulk of subsidies will go to the more developed regions where the biggest farms and utilized farmland are located.

There will be also significant EU funds for rural development exceeding 4.7 times the relevant pre-accession level. This amount of resources will let more and relatively smaller farms to get access to public support scheme and invest in modernization of enterprises. Furthermore, new essential activities will be effectively funded such as: commercialization and diversification of farming; introduction of organic farming; maintaining productivity, biodiversity; agri-environment of protection, animal welfare; support for less-favored areas and regions with environmental restrictions etc. All these will bring additional employment and income for farmers, and increase economic and environmental sustainability of farms.

Mostly bigger farms would be able to participate in public support programs because they have a superior managerial and entrepreneurial experience, available resources, possibilities for adaptation to new requirements for quality and other standards, potential for preparing and wining projects etc. Besides, the actual system of governance of public programs would less likely change overnight. Therefore, agrarian and rural development funds will continue to benefit exclusively the largest structures and the richest regions of the country; and more abuses will likely take place; and CAP support will not contribute to decreasing economic and eco discrepancy between farms, sectors, and regions.

The CAP implementation will improve the environmental performance of farms. There is a mandatory requirement for farms to "keep the farmland in a good agricultural and environmental status" in order to receive direct payments and participate in public programs. Moreover, direct payments would likely induce farming on currently abandoned lands, and improve environmental situation and biodiversity. Furthermore, there will be a huge budget allocated for special environmental measures (going beyond the "good farming practices") ${ }^{21}$. A great number of farms will have economic incentives to take part in various agri-environmental and animal welfare programs.

The CAP measures will affect positively the environmental performance of large business farms. Namely these enterprises (and potential big polluters) will be under constant administrative control and severe punishment (fines, losing licenses, and ceasing activities) for obeying new environment and animal welfare standards. Therefore, they will be strongly interested in transforming their activities according to the new eco-norms making necessary eco-investments, changing production structures etc. Moreover, larger producers will be motivated to participate in special agro-environmental and biodiversity programs, since they have lower costs (potential for exploring economies of scale and scope) and higher benefits from such long-term public contracts.

The experience of developed countries demonstrates that some of the terms of the specific contracts for environment and biodiversity preservation, animal welfare, keeping tradition etc., all they are very difficult (expensive) to enforce and dispute (Dupraz et al., 2004). In Bulgaria the rate of compliance with these standards will be even lower because of the lack of readiness and awareness, insufficient control, ineffective court system,

21 The National Strategy Plan for Rural Development for 2007-2013 allocates budget for "preservation of national resources and improvement of countryside" amounting $€ 623.3$ million (27.1\% of the total funding). 
domination of "personal" relations and bribes etc. (Bachev, 2007b). Correspondingly, more farms than otherwise would enroll will participate in such schemes (including the biggest polluters and offenders). Subsequently, the outcome of implementation of that sort of instruments would be less than the desirable ("European") level.

More to the point, direct costs and lost income for conforming to the requirements of the special programs in different farms will vary considerably, and they will have unequal incentives to participate. Having in mind the voluntary character of the most CAP support instruments, we should expect that the biggest producers of negative impacts (large polluters and non-compliant with modern quality, agronomic, biodiversity, animal welfare etc. standards) will stay outside of these schemes since they would have the highest environment enhancement costs. On the other hand, small contributors would like to join since they would not command great efforts (and additional costs) comparing to the supplementary net benefit. Moreover, the Government is less likely to set up high performance standards because of the perceived "insignificant" environmental challenges, the strong internal political pressure from farmers, and the possible external problems with the EU control (and sanctions) on cross-compliance. Therefore, CAP implementation will probably have a modest positive impact on the environment performance of Bulgarian farms.

The public support and new public demand will give a push to further development of market modes such as organic farming, industry driven eco-initiatives (eco-labeling, standards, professional codes of behavior), protected high quality products (Protected Designation of Origin, Protected Geographical Indication, and Traditional Specialty Guaranteed), system of fair-trade, production of alternative (wind, manure) energy at farm etc. For instance, the significant EU market and lower local costs will create strong incentives for investment in organic and specific productions by the large enterprises - farms, partnerships and joint ventures (including with non-agrarian and foreign participants). The small farms would have less capacity to put together or find necessary capital and expertise for initiating, developing, certifying and marketing. Besides, the coalition (development, management, and exit) costs between small-scale producers are extremely high to reach the effective operation level (allowing exploring technological economies of scale and scope). Therefore, the later will either stay out of these new businesses or have to integrate into larger or non-farm ventures. However, assuring the effective traceability of the origin and quality for small farms is very costly and they are not preferable partner for integrators (processor, retailers, and exporters). On the other hand, the internal market for organic and specialized farm products would unlikely develop fast having in mind a low income of population and the lack of confidence in public and private system of control. Beside, when the appropriability of absolute and contracted rights is low (easy to copy a product, difficult to detect and punish offenders) the private governance fails to organize activities in a socially optimal scale (under-investment and under supply of product).

Many semi-professional and professional livestock farms will be less sustainable in a middle-term because of the low productivity and non compliance with the EU quality, hygiene, animal welfare and eco-standards (Bachev, 2007b). A few numbers of these farms will be able to adapt through specialized investment for enlargement and conforming to the new institutional restrictions. Meanwhile, the EU pressure for enforcement of standards in commercial sector will increase and lead to closure or take-over of a greater part of livestock farms. The improvement of manure management and reduction of animals will be associated with a drop of the environmental burden by the formal sector (less over-grazing, manure production and mismanagement). 
On the other hand, only few subsistence farms will likely undertake market orientation and extend their present scale because of the lack of entrepreneurship, resources, advanced age of farmers, and insufficient demand for farm products (Bachev, 2007b). For authorities will be practically impossible (costly or politically undesirable) to enforce the official standards in that huge informal sector of the economy. Therefore, massive (semi)subsistence farming with primitive technologies, poor food safety, environmental and animal welfare standards will continue to exist in years to come.

Some economic needs such as economizing on scale and scope or high interdependency of assets would bring about a change in size and governance of individual farms and/or evolution of group organization, cooperation, and joint ventures. For instance, a big interdependency of activities would require concerted actions for achieving certain eco-effect; a high asset dependency between livestock manure (over) supplier and nearby (manure demanding) organic crop farms would necessitate a coordination etc. A special governing size and/or mode will be also imposed by some of the institutional requirements. For example, a mandatory minimum scale of activities is set for taking part in certain public programs (e.g. marketing, agri-ecology, biodiversity, organic farming, tradition and cultural heritage); signing a 5 year public environmental contract would dictate a long-term lease or purchase of managed land etc.

Some production cooperatives would also profit from their comparative advantages (interdependency and complementarily to individual farms, potential for exploring economy of scale and scope on institutionally determined investment, adapting to formal requirements for support, using expertise, financing and executing projects, non-for-profit character etc.), and extend their activities into eco-projects, environmental services, eco-mediation between members etc.

Principally, the hybrid modes (public-private partnership) are much more efficient than the pure public forms given the coordination, incentives, and control advantages (Bachev, 2007a). In majority of cases, the involvement of farmers, farms organizations and other beneficiaries increases efficiency - decreases asymmetry of information, restricts opportunisms, increases incentives for costs-sharing, reduces management costs etc. For instance, a hybrid mode is more appropriate for supplying non-food services by farmers such as preservation and improvement of biodiversity, landscape, historical and cultural heritages. That is determined by the farmers information superiority, the strong interlinks of activity with the traditional food production (economy of scope), the high assets specificity to the farm (farmers competence, a high cite-specificity of investments to the farm and land), and the spatial interdependency (the need for cooperation of farmers at regional or wider scale), and the farm's origin of negative externalities.

Moreover, enforcement of most labor, animal welfare, biodiversity etc. standards is often very difficult or impossible at all. That is particularly troth for huge informal sector of the economy. Here individual "punishments" do not work well while overall damages from incompliance are immense. That is why policies should be oriented to market orientation of subsistence farms, support and incentives for collective modes, and eco-programs for informal farms and groups. Principally, public support to voluntary environmental initiatives of farmers and rural organizations (informing, training, assisting, funding) would be much more effective than mandatory public modes in terms of incentive, coordination, enforcement, and disputing costs.

Furthermore, involvement of farmers, farmers organizations, and interests groups in priority setting and management of public programs at different level is to be 
institutionalized in order to decrease information asymmetry and possibility for opportunism, diminish costs for coordination, implementation and control, and increase overall efficiency and impact.

An immediate result of new market and public opportunities for getting additional income (profiting) from environmental products and services will be an amelioration of the economic performance and overall sustainability of many farms and rural households.

There are still a number of "blank points" in adaptation of EU regulations in Bulgarian agriculture. For instance, "the whole farm" is a subject of support in agri-environmental measures (e.g. organic farming) but its borders are not defined at all in the national legislation. That will create serious difficulties since land and other resources of the majority of farms are considerably fragmented and geographical dispersed.

Furthermore, all surveys show that many of the specific new regulations are not well known by the implementing authorities and majority of farmers (Bachev, 2007b). The lack of readiness and experiences would require some time lag until the "full" implementation of the CAP. The later will depend on the pace of building an effective public and private capacity, and training of (acquiring learning by doing experience by) bureaucrats, farmers, and other agrarian agents. Besides, most of the farm managers have no adequate training and managerial capability, and are old in age with a small learning and adaptation potential ${ }^{22}$. Therefore, there will be significant inequalities in application (enforcement) of new laws and standards in diverse sectors of agriculture, and farms of different type and size, and various regions of the country.

Last but not least important, there will be enhance competition for environmental resources between different industries and interests. That would push further overtaking the natural resources away from the farm governance and change into non-agricultural (urban, tourism, transport, industry etc.) use. The needs to compete for and share resources would also deepen conflicts between various interests and social groups, regions, and even with neighboring states. All that would require a special governance (cooperation, public order, hybrid form) at local, national and transnational scales to reconcile conflicts in the benefit of an effective environmental management.

According to the experts the implementation of EU CAP will affect most aversely sustainability of dairy farms in the country (Bachev, 2007b). Our survey of dairy farms has found out that different type of farms have unequal capacity for adaptation to new EU requirements and unlike expectation about the probable impact of CAP on their farms ${ }^{23}$.

A great number of farms have no sufficient capacity for adaptation to new institutional requirements for the dairy sector (Table 2). That is particularly truth for the small-scale unregistered producers which dominate the sector. Bigger milk producing firms on the other hand, indicate they process a big or good capacity in terms of "knowledge on new regulations", "skills and knowledge for adaptation", "improvement of quality and hygiene", "improving animal welfare", and "improving eco performance". The potential for adaptation to new environment and animal welfare requirements of the few cooperatives in the area is low. Furthermore, only a third of dairy holdings believe their production capacity corresponds to the modern requirements of competition, productivity, and justification of improvement of environmental performance and animal welfare. Merely one-seventh of

${ }^{22}$ Farm managers older than 45 and 65 are $85 \%$ and $40 \%$ accordingly (MAF, 2004).

${ }^{23}$ Survey was carried out in summer 2007 and included 66 commercial dairy farms of different type from two major milk producing regions - Plovdiv and Pazarjik. 
dairy farms have potential (internal capacity, access to outside sources) to fund necessary investment associated with the adaptation to new EU norms and standards.

Table 2: Share of farms with big and good capacity for adaptation to new EU requirements for dairy sector (per cent)

\begin{tabular}{lcccc}
\hline \multicolumn{1}{c}{ Farms capacity } & Unregistered & Firms & Coops & Total \\
\hline $\begin{array}{l}\text { Extend of knowledge on new } \\
\text { requirements }\end{array}$ & 22.73 & 63.64 & 100 & 38.24 \\
$\begin{array}{l}\text { Available skills and knowledge } \\
\text { for adaptation }\end{array}$ & 22.73 & 54.55 & 100 & 35.29 \\
Available production capacity & 27.27 & 45.45 & & 32.35 \\
Improvement of quality and hygiene & 36.36 & 72.73 & 100 & 50.00 \\
standards & 31.82 & 72.73 & & 44.12 \\
Improving animal welfare & 31.82 & 54.55 & & 38.24 \\
Improving environmental performance & 9.09 & 27.27 & & 14.71 \\
Finding necessary investment & & & & \\
\hline
\end{tabular}

Source: survey data

Table 3: Expectation for impact of EU CAP implementation on your farm (percent of farms)

\begin{tabular}{lcccccc}
\hline \multicolumn{1}{c}{ Impact on: } & \multicolumn{2}{c}{ Unregistered } & \multicolumn{2}{c}{ Firms } & \multicolumn{3}{c}{ Total } \\
& + & - & + & - & + & - \\
\hline Volume of production & 22.73 & 9.09 & 36.36 & 27.27 & 26.47 & 14.71 \\
Income of farm & 22.73 & 9.09 & 45.45 & 18.18 & 29.41 & 14.71 \\
Technology of production & 13.64 & 4.55 & 54.55 & 9.09 & 26.47 & 5.88 \\
Investment & 18.18 & 4.55 & 45.45 & 18.18 & 26.47 & 8.82 \\
Products quality & 18.18 & 0.00 & 45.45 & 0.00 & 26.47 & 0.00 \\
Access to public programs & 9.09 & 4.55 & 54.55 & 9.09 & 23.53 & 8.82 \\
Improvement of animals care & 13.64 & 0.00 & 45.45 & 9.09 & 26.47 & 2.94 \\
Improvement of care for & & & & & & \\
environment & 9.09 & 0.00 & 54.55 & 9.09 & 23.53 & 2.94 \\
Development of infrastructure & 9.09 & 0.00 & 54.55 & 9.09 & 23.53 & 2.94 \\
Opportunities for new income & 18.18 & 9.09 & 36.36 & 9.09 & 23.53 & 8.82 \\
Social status of your household & 13.64 & 4.55 & 45.45 & 27.27 & 23.53 & 11.76 \\
\hline Source: survey data
\end{tabular}

Source: survey data

(+) - positive impact; (-) - negatove impact

Our survey has also found out that a great part of unregistered farms believes that the introduction of CAP measures will have a "neutral impact" on their income, volume and technology of production, investment level, product quality, access to public programs, 
improvement of environmental care, improvement of animal welfare, development of infrastructure, possibilities for new income generation, and social status of farm households (Table 3). On the other hand, a bulk of firms expects a "positive" effect in all above directions. The cooperatives are merely optimistic for the CAP affect on the improvement of animal welfare while expectations for its impact on income and access to public programs are negative.

Lastly, just under $12 \%$ of surveyed farms report they do not need to make any considerable changes in order to keep selling milk in new conditions. Almost two-third of them says they have to make progressive changes in "hygiene of production", more than $41 \%$ in "milk quality", and $26 \%$ in "volume of production" and "animal care". For more than 35\% of farms the adaptation to new requirements for safety, quality, eco-conditionality etc. is associated with "significant costs and investment" and raising "amount and intensity of labor".

\section{Conclusions}

Our analysis of environmental management in Bulgarian agriculture let us identify the major environmental problems and risks, and specify the driving factors for their emergence and persistence, and make more realistic forecast about the eco development. We have proved that the contemporary development of Bulgarian agriculture is associated with specific (and quite different from other European states) environmental challenges, some of them reaching up to the point of no or limited management (e.g. degradation of soil quality, erosion etc.). That has been a result of the specific institutional and governing structure evolving in the sector during the past 20 years. The comparative institutional and transaction costs analysis also shows that implementation of the common EU policies will give unlike results in "Bulgarian" conditions. In short and medium term it most likely will enlarge income, technological and environmental discrepancy between different farms, sub-sectors and regions. In a longer-term environmental hazard(s) caused by the agricultural development will enlarge unless effective public and private measures are taken to mitigate the existing and emerging environmental problems and risks.

The identification of efficiency, complementarities, and sustainability of different modes of environmental governance has a substantial importance for the improvement of public policies, and individual and business strategies. Firstly, it helps anticipate possible cases of market, private sector, and public (community, Government, international assistance) failures, and design appropriate modes for public intervention - assistance, regulation, in-house organization, partnership with private sector, fundamental institutional and property rights modernization. In particular, it facilitates formulation of specific policies and institutional framework to overcome the existing environmental problems, and safeguard against the possible eco-risks, and avoid the severe environmental challenges in developed countries. Next, it could assist agrarian and rural agents organizational modernization and individual and collective actions in successful adaptation to changing economic, institutional and natural environment. 


\section{References:}

Bachev H. (2004): Efficiency of Agrarian Organizations, in: Farm Management and Rural Planning No 5, Kyushu University, Fukuoka, pp. 135-150.

Bachev H. (2006): Governing of Bulgarian Farms - Modes, Efficiency, Impact of EU Accession, in: Agriculture in the Face of Changing Markets, Institutions and Policies: Challenges and Strategies, J.Curtiss, A.Balmann, K.Dautzenberg and K.Happe (eds.), IAMO, Halle (Saale), pp. 133-149.

Bachev H. (2007): Governing of Agrarian Sustainability, ICFAI Journal of Environmental Law, Vol. VI, 2, Hyderabad, pp. 7-25.

Bachev H. (2008): Governing of Environmental Challenges and Sustainability of Bulgarian Agriculture, in: Environmental Challenges and Human Security: Recognizing and Acting on Hazard Impacts, P.Liota (ed.), Springer, Amsterdam.

Bachev H. and M. Kagatsume (2002a): Restructuring of Bulgarian Agriculture, in: Agricultural Restructuring and Environmental Issues in Eastern Europe under the Transition Process, Graduate School of Agriculture, Kyoto University, Kyoto, pp. 180-203.

Bachev H. and M.Kagatsume (2002b): Governing of Financial Supply in Bulgarian Farms, The Natural Resource Economics Review No 8, pp.131-150.

Bachev H. and M.Kagatsume (2005): Assessment of Farm Support Policies and Likely Impact of CAP Implementation on Farm Structures and Sustainability in Bulgaria, The Natural Resource Economics Review No 11, pp.173-192.

Bachev H. and M.Tsuji (2001): Structures for Organization of Transactions in Bulgarian Agriculture, Journal of the Faculty of Agriculture of Kyushu University No 46 (1), pp. 123-151.

Bentcheva N. and S. Georgiev (1999): Country Report on the Present Environmental Situation in Agriculture - Bulgaria, in: Central and Eastern European Sustainable Agriculture Network, Proceedings FAO workshop, Gödöllö.

Coase R. (1960): The Problem of Social Costs, Journal of Law and Economics 3: 1-44.

Dupraz P., K. Latouch, and F. Bonnieux (2004): Economic Implications of Scale and Threshold Effects in Agri-environmental Processes, Paper presented at the 90 EAAE Seminar, October 27-29, 2004, Rennes.

Furuboth E. and R. Richter (1998): Institutions and Economic Theory: The Contribution of the New Institutional Economics, The University of Michigan Press, Ann Arbor. 
Gatzweiler F. and K. Hagedorn (eds.) (2003): Institutional Change in Central and Eastern European Agriculture and Environment, CEESA/FAO Series, FAO and Humboldt University of Berlin, Berlin.

North D. (1990): Institutions, Institutional Change and Economic Performance, Cambridge University Press, New York.

OECD (2000): Review of Agricultural Policies: Bulgaria, OECD, Paris and Sofia.

Sumelius J. (2000): A Review of State of Sustainability of Farming Systems in the Selected Central and Eastern European countries, FAO, Rome.

Vassilev Hr., C. Christov, V. Hristova, and B. Neshev (2006): Greenhouse Gas Emissions in Republic of Bulgaria 1988, 1990-2004, National Inventory Report 2004, Ministry of Environment and Water, Sofia.

Williamson O. (1996): The Mechanisms of Governance, Oxford University Press, New York. 